\title{
HACIA UNAS PEDAGOGÍAS PARA EL POST-ACUERDO TERRITORIALIZANDO LA PAZ DESDE LA ESCUELA Y LA EDUCACIÓN ${ }^{1}$ (TEXTO EN CONSTRUCCIÓN)
}

\author{
Towards pedagogies for the post-agreement \\ Territorializing peace from school and education \\ (Text under construction)
}

Marco Raúl Mejía Jiménez*

Mejía, M.R. (2016). Hacia unas pedagogías para el post-acuerdo territorializando la paz desde la escuela y la educación. Revista PACA, 9-33

"Testimoniar, respetar, cuidar renunciar, ser responsable de todo y de tod@s es un hacer posible y esencialmente ético, por estar en la esfera de nuestro poder. La conciencia moral es fruto del proceso reflexivo y de la enseñanza de la ética como ejercicio pedagógico de responsabilidad tanto en cuestiones de frontera como en lo cotidiano."

Lourenco Zancanaro ${ }^{2}$

*Doctor en Educación. Planeta Paz, Expedición Pedagógica Nacional. Email: marcoraulm@gmail.com ${ }^{1}$ Notas en elaboración a partir de los desarrollos del proyecto PlanetaPaz.

${ }^{2}$ De Pane, Cristian, Barchifontaine, B. y otros. Bioética. Algunos desafíos científicos. São Camilo, São Paulo. Ediciones Loyola. 2001. 


\section{Un marco contextual}

a. Un país construido sobre múltiples conflictos: en el Estado, en la de sus territorios, en las fronteras trazadas, en los modelos de desarrollo, en la constitución de las élites locales, en los procesos políticos.

b. Una construcción con piso en la desigualdad, que genera confrontación a diferentes niveles en lo local, en lo regional, en lo nacional, y se termina con la exclusión simbólica o física de los oponentes, que ha construido socialmente una forma de hacer política ligada a la violencia

c. Un país desigual en la redistribución de los recursos, del territorio, del ingreso, de la propiedad, lo cual se convierte en la dinámica de los múltiples conflictos sobre el territorio

d. Desigual también en acceso a los DESCA a nivel laboral, de la seguridad social, en ingresos, pensiones, salud, en la repartición a los diferentes territorios

e. Construye desde algunos sectores la búsqueda de una paz con justicia social y enmarca un escenario de negociación con los actores que busca mutar las formas de la violencia.

\section{Enseñanzas históricas}

a. Se han ensayado múltiples ejercicios de negociación del conflicto. En algunos casos incorporando a los contrincantes políticos a la dinámica de la sociedad

b. Nunca se han resuelto los desequilibrios sociales, económicos y políticos que están a la base del conflicto

c. Siempre se ha considerado necesaria la negociación para buscar salir de la polarización y permita construir sociedad con mecanismos en los que se regule el conflicto

d. Siempre ha estado la paz planteada como el desarme y no como la erradicación de la vida social de la condición de guerra en que se ha vivido

e. La paz termina estando planteada entre el silencio de las armas y el lugar los derechos políticos de todos y todas.

3. La paz como tarea política

a. Como creación de condiciones políticas, sociales y económicas para entender éstas en clave de conflicto y como parte constitutiva del desarrollo de la sociedad. 
b. Como erradicación de la vida social del estado de guerra en que se vive

c. Construir un aprendizaje del conflicto que garantice que nadie recurra a estrategias bélicas para eliminar física o simbólicamente al adversario

d. Construir mecanismos político-democráticos que permitan la regulación, cualificación o resolución de los conflictos.

e. Impedir la militarización legal o ilegal de la vida civil, evitando una socialización bélica.

4. Una paz desde y en las regiones

a. Es construir capacidad de manejo y elaboración e conflictos desde el mundo social popular

b. Que los conflictos sociales no se conformen en conflictos armados

c. Incorporar lo público popular a la construcción de la política, haciendo que la paz allí sea la construcción de lo público

d. Incorporar las regiones y los movimientos sociales desde su especificidad a la construcción de un estado de derecho

e. Un Estado que refunda la democracia y se haga copartícipe frente a la sociedad para construir nuevos derechos.

5. La educación como sistema y las resistencias desde los territorios

a. Parte de un proyecto transnacionalizado manejado desde organismos multilatelares y resistido desde procesos políticos-culturales que han dado lugar a los movimientos sociales de la educación

b. Una propuesta construida desde la hegemonía económico-cultural euroamericana y una resistencia desde el pensamiento de la colonialidad y de las epistemes del sur.

c. Una escuela homogénea desde las competencias y los estándares bajo el proyecto del STEM (ciencias naturales, tecnología, ingeniería y matemáticas, con una respuesta crítica de las capacidades y de los sistemas sociales del conocimiento y el saber.

d. Una escuela y una educación como proyecto transnacional en lo nacional a través de leyes nacionales de educación con matriz transnacional y la resistencia construida desde las discusiones de la pertinencia y cómo se territorializa.

e. Un control de la territorialización educativa desde los procesos de calidad estandarizados y una respuesta de infinidad de propuestas desde 
la educación propia, la educación popular, la educación intercultural, entre otras.

6. Tarea central de la escuela: transformar educativamente el conflicto.

\section{Construyendo los nexos entre el conflicto cotidiano y la vida social ${ }^{3}$}

"Una sociedad mejor es una sociedad capaz de tener mejores conflictos, de conocerlos y de contenerlos. De vivir no a pesar de ellos, sino productiva e inteligentemente en ellos. Que sólo un pueblo escéptico sobre la fiesta de la guerra y maduro para el conflicto es un pueblo maduro para la paz."

Estanislao Zuleta ${ }^{4}$

Esta cita pudiera servir a manera de síntesis de lo que intento desarrollar en esta ponencia, ya que asumir el problema de la paz pasa radicalmente por asumir el conflicto de otra manera y la manera como nos relacionamos los seres humanos en medio de él. Implica reconocer que asumir educativamente el conflicto significa iniciar ya un proceso social y educativo, especialmente en las nuevas generaciones, para construir las bases de un mediano plazo en el cual el manejo del conflicto desde temprana edad nos haga maduros, no para resolverlo, ya que no es posible en muchas ocasiones, sino para vivir, manejándolo y convirtiéndolo en dinamizador de nuestro crecimiento.

Esta mirada del conflicto exige recomponer la mirada sobre la otra, el otro, los otros en un mundo como el de hoy, en donde no sólo atizan las violencias de todos los tamaños sino también los procesos de desigualdad, de subsumir lo diferente en un mundo homogeneizado, parece ser una tentación de todos los poderes grandes y pequeños de este tiempo. Por

\footnotetext{
${ }^{3}$ Este trabajo es una continuación y ampliación de ponencias previas presentadas en seminarios nacionales e internaciones sobre esta problemática, en especial de la presentada al Simposio Peligro Oportunidad: Relación entre conflicto cotidiano y política en Colombia hoy, convocado por la Universidad de Antioquia, EMDA Fundación para el Bienestar Humano, y el IPC. Medellín, agosto 29-31, 2001. ${ }^{4}$ Zuleta, Estanislao. El elogio de la dificultad y otros ensayos. S/ciudad. Fundación Estanislao Zuleta Sáenz Editores. 1994. Pág. 13.
} 
ello, para desarrollar este trabajo en el cual pretendo plantear como hipótesis central que en el entrecruce de todas las reflexiones políticas, sociales, económicas sobre la violencia y la guerra existe un peligro al olvidar los énfasis culturales y educativos de esa problemática, intentando hacer una primera aproximación a la búsqueda desde la multiculturalidad crítica y el conflicto. Casi podríamos afirmar que la paz es un problema demasiado serio para dejarlo sólo en manos de los políticos.

Por ello, la reflexión que intento desarrollar busca construir un hilo conductor en torno a la manera como un educador que viene del campo específico de la educación popular intenta entender las claves educativas y culturales para encontrar unos ejes embrionarios de los cómo de una intervención educativa que no cree que la paz sea la simple ausencia de la guerra. Requiere entrar en el imaginario de nuestras poblaciones en todas las clases y razas, así como en los géneros para construir una capacidad de manejo del conflicto que nos permita creer que es posible en el mediano y largo plazo construir una cultura de la paz.

Esta reflexión todavía embrionaria es parte de un texto mayor en construcción, que se mueve en un horizonte de hacer un análisis de la globalización capitalista de estos tiempos, sus esfuerzos por construir una homogeneización y la manera como la diferencia y la desigualdad arrebatan a esa ilusión universalista los intentos de construir un mundo hegemónico desde las nuevas formas del poder.

Allí brilla con luz propia la multiculturalidad crítica como forma privilegiada de enfrentar la homogeneización y dejándonos asomar el conflicto como eje de una nueva construcción que hace visible diferencia, desigualdad, y formas del poder en un camino que impone formas de intervención que sean capaces de romper con nuestros núcleos de verdad tanto en el pensamiento como en la acción, en nuestros deseos y emociones. Pero enfrentar esta circunstancia en un horizonte crítico significa ante todo la capacidad de deconstruir los caminos recorridos y las formas como esa cultur a de verdad anida en nuestros cuerpos, en nuestras mentes, en nuestras pasiones. En este planteamiento, para nosotros se convierte en central la negociación cultural como eje metodológico que permite reconstruir también una pedagogía del conflicto que sea capaz en la negociación de lo diferente y en la lucha por enfrentar las desigualdades 
y las exclusiones, de reconstruir la solidaridad como un nuevo lugar de la acción humana. ${ }^{5}$

Pero para realizar esto se hace necesario asumir el conflicto, en una sociedad como la colombiana, atravesada por múltiples conflictos, algunos de los cuales hemos derivado en violencia, no como un hecho no solamente político o psicológico o cultural, sino construirlo como una integralidad que pueda dar cuenta de las múltiples facetas y caras que él tiene y de la manera como hace presencia permanente en nuestras vidas y exige de nosotros un aprendizaje para enfrentarlo, resolverlo y darle vía a los nuevos conflictos que irán poco a poco construyendo nuestro devenir humano.

Señalar la necesidad del aprendizaje de su manejo habla inmediatamente de que es necesario constituir el conflicto desde una mirada educativa para darle un tratamiento pedagógico que nos permita construir los dispositivos específicos para asumirlo y convertirlo en dinámica de cambio subjetiva y en los procesos de socialización mediante actividades que reconstruyen tejido social.

Plantearse educativamente el conflicto es ante todo tener la profunda creencia de que es posible darle un tratamiento de economía de la agresividad mediante el cual las personas, las instituciones, los grupos sociales pueden hacer un acto de intervención sobre ellos para producir con su dinámica una reorganización de la sociedad desde el manejo mismo de los conflictos en el reconocimiento de los intereses específicos de estos grupos que deben ser negociados.

\section{La paz, mucho más que el fin de la guerra}

Normalmente, en nuestros referentes sociales y mediatizados por toda la fugacidad del fenómeno comunicativo, a veces se va construyendo un imaginario en el cual el sentido común de la mayoría de habitantes de nuestro país comienza a imaginar que la paz es un momento en el cual no

\footnotetext{
${ }^{5} \mathrm{De}$ alguna manera considero este texto un desarrollo del libro que escribí con Gabriel Restrepo sobre democracia: Restrepo, Gabriel y Marco Raúl Mejía. Formación y Educación para la Democracia en Colombia: apuntes para un Estado del Arte. Santa Fe de Bogotá. Instituto para el Desarrollo de la Democracia Luis Carlos Galán. 1997.
} 
existan grupos armados y se acabe la violencia guerrillera. Pero el problema que a veces genera esa cultura light en la rapidez y la multiplicidad de la información, es olvidar que la paz es una cultura que se construye y que debe ser propiciada en los contextos de acción de los seres humanos en sus relaciones sociales generales y cotidianas que se constituyen a través de sus múltiples determinaciones.

Es decir, la paz toca los contextos de acción y los actores involucrados en el mapa de las múltiples guerras. En ese sentido, va a requerir un esfuerzo en donde los procesos micro (mundo local), meso (procesos nacionales) y macro (procesos internacionales), coincidan en el elemento que es articulador de ellos y es el ser humano. Ese concreto de carne y hueso que sueña, cree y espera desde imaginarios que anidan en su espíritu y en su cuerpo y en la manera como ocupa el territorio que habita, intenta reconstruir su vida y sus esperanzas.

Por eso, reconocer que la ausencia de la guerra no es la paz, pero que es parte de ella, significa tener la capacidad de reconocer también esos otros elementos, los cuales hacen que la paz no sea posible. En un primer lugar, la violencia estructural que negando las necesidades humanas primarias produce una violencia que silencia las desigualdades. Igualmente, las violencias en que están insertos aquellos que apostando por mejorar la calidad de vida no encuentran la manera de enfrentar los desequilibrios del poder, que no les permite satisfacer esos nuevos niveles de necesidades. De la misma manera, aquellos que buscan hacer posible un desarrollo humano que construye desde la diferencia cultural un mundo ecológicamente viable pero que tienen su límite también en un mundo que se niega a una reducción voluntaria de sus necesidades.

También están las violencias generadas por aquellos que, incluidos en situaciones de opresión, ven reducida su forma de existencia a niveles inhumanos de controles organizados desde esferas invisibles en donde ellos no alcanzan a reconocer el porqué de sus situaciones límite. Pudiéramos afirmar que estas múltiples violencias tienen tras de sí grandes y pesadas reflexiones y análisis que las explican bajo diferentes circunstancias y terminan haciendo de la paz una búsqueda teórica. Y, en ocasiones, conflicto de discursos. 
Por ello, es común ver en nuestra realidad esencias que se mueven, poderes que se imponen, la satanización del otro y la dificultad para entender cuáles son las razones del otro en medio del conflicto. Todos sueñan, pero cada uno sueña a su manera. No va a ser posible pensar la paz si no logramos unas transformaciones profundas en los imaginarios que hemos construido en nuestra vida cotidiana y con los cuales nos relacionamos con nosotros mismos, con los otros, y desde los cuales construimos la violencia cotidiana en el hogar, en el lugar de trabajo, en la sociedad, reconstruyendo en nuestro mundo pequeño las formas mediante las cuales se hace visible el que no poseemos una cultura para manejar el conflicto. Por ello, la paz es un trabajo de todos/as desde la experiencia individual en los niveles de responsabilidad de cada uno/a con su cuerpo, con su mente, con su deseo, con su pareja, con su grupo más cercano y, en alguna medida, con la sociedad.

Por ello un/a educador/a no puede ver la paz como el fin de la guerra, sino en un proceso de mediano y largo plazo que desactive las formas culturales de la violencia y construya procesos pedagógicos que nos enseñen a manejar los conflictos, sin ocultarlos, reconociendo en ellos la clave de nuestro crecimiento, haciendo de ellos el crisol del alma humana y permitiéndonos hacer una economía política de la agresividad.

\section{Un lugar para la diferencia y la desigualdad}

Uno de los problemas centrales con el cual nos encontramos en los procesos de globalización política, social y económica que se dan en nuestras realidades, es la manera como se producen discursos homogéneos donde pareciera que todos somos lo mismo. Allí tanto como ciudadanos, y en cuanto hijos de la democracia, terminamos siendo parte de una identidad formal vacía, en donde la identidad pareciera estar construida en cuanto se apagan las diferencias, convirtiéndose muchos de estos discursos en las formas que construye una élite propiciadora de esa universalidad en la cual los procesos de diferenciación parecen extinguirse.

Hemos terminado convertidos en ciudadanos del mundo y se construye una explicación en la cual se ha perdido la cultura que nos daba identidad y unidad. Por eso, son tiempos en los cuales repensar las relaciones entre identidad y diferencia termina convirtiéndose en retardataria en cuanto 
esto pareciera ser de un mundo que ya ha clausurado los problemas de lo local, de la enunciación y del posicionamiento cultural.

Reconstituir la diferencia significa la capacidad de buscar prácticas de significación para grupos específicos que constituyen también relaciones políticas y económicas, relaciones que en algunos casos se oponen. No es sólo el pluralismo cultural como sueña el liberalismo, ya que la diferencia va a tener un efecto histórico hacia adelante y hacia atrás. Va a ser enfrentar la armoniosa cultura común con la cual sueñan los grupos más conservadores para mantener una diferenciación que les otorga poder.

Por ello, reconocer que la diferencia es un elemento central en las búsquedas significa la capacidad de ir tras la huella de actores, la manera como esas historias escondidas pero presentes en su cuerpo y en sus relaciones configuran una manera de ver el mundo que no puede emerger porque los núcleos básicos del poder no le permiten visibilizar esa historia de minorías o de grupos mayoritarios acallados.

Frente a una tendencia mecánica de la globalización económica, que tiende a producir un análisis de homogeneización a todos los otros niveles, es necesario ir a la búsqueda de lo diferente, de tal manera que produzca en nosotros una descentración, en cuanto va a colocar la fuerza en reconocer "mis particularidades" y la manera cómo las formas dominantes tienen un centro que se constituye precisamente en el ejercicio de negar lo diferente que es aquello que aparece desde su centralidad como las "márgenes", haciendo que todo lo diferente sea parte de lo otro no reconocido oficialmente $y$, por lo tanto, subsumido en esa negación.

Comenzar por reconocer la diferencia significa la capacidad de construir una relación entre mi mundo de sentidos y de acciones y desde mi identidad, de establecer lo otro que no es como lo mío. Esto va a permitir construir de otra manera mi relación social, en cuanto allí voy a poder producir "mi versión". Es decir, el lugar desde el cual yo, con mi huella, produzco mi texto, surgido desde mi praxis, me abro a la búsqueda de la intertextualidad (de instituciones, personas, grupos humanos), rompiendo en mí la estructura de poder que no deja emerger lo diferente.

De esta manera, produzco desde mi experiencia el reconocimiento de lo 
"otro" hecho de mil maneras por las huellas que lo constituyen, y en ese sentido reconoce que el encuentro posible para construcción de proyectos comunes tiene mil senderos.

La diferencia se establece como campo de experimentación, es decir, no como límite, como barrera, sino como exigencia a construir los puentes a través de los cuales surja lo común a partir de la conjunción entre lo necesario y lo imposible.

Es el momento en el cual la diferencia me coloca en la incertidumbre. El reconocimiento de lo otro (la otredad) me coloca frente a la necesidad de perder la certeza y entrar en el camino de ver aquello otro como lo que complementa, lo que construye más totalmente (en teorías, en instituciones, en personalidad, en el mundo de lo social). Es el otro, que al ser crítico, me emerge como diferente y real, y en su diferencia pareciera como una amenaza para la verdad del sistema en el que estoy ubicado y que he construido en torno mío. En un conflicto bien manejado, ese otro lo que me muestra es la relatividad de lo mío, construyéndome además lo provisional de mis posiciones. Es allí donde se generan las formas del miedo y tras ellas la agresividad o el desconocimiento del otro.

Nos situamos frente a una construcción de lo colectivo desde múltiples lugares, pero que, ubicando la diferencia como elemento central, me constituye como ser social con responsabilidades colectivas y que son necesarias de re-construirse. Por ello, siempre la lógica de lo solitario no existe, porque estamos frente a unos procesos de individuación en los cuales desde mi yo asumo lo colectivo mediante la construcción de comunidades (humanas, intelectuales, académicas, de profesión, etc.).

\section{La multiculturalidad enfrenta la homogeneización de la globalización}

Hoy aparece como un hecho el mundo globalizado que, explicado como un desarrollo de las fuerzas productivas, desde las revoluciones científicas y tecnológicas, adquiere en el control del capital financiero, el desmonte del Estado de Bienestar y el predominio del mercado, su forma neoliberal.

Una de las maneras como esa forma globalizada atenta contra la diferencia es su pretensión de construir una cultura global unificada y, por lo tanto, 
producir subjetividades e identidades más o menos homogéneas que tendrían como realidad una especie de pre-formatividad (a priori) de la acción y de la historia, produciendo una homogeneización que oculta experiencias de vida y experiencias sociales extremadamente diferentes, además del profundo desfase que ha mostrado entre economía y ética y moral.

Esa homogeneización aparece con más fuerza en el mercado que, con el señuelo de ser una expresión y convergencia de lo diferente, intenta ocultar el conflicto que significa aceptar lo diferente. Es ahí cuando estalla en sus manos esa manera en la cual lo diferente emerge como desigual. En ese sentido, aparecen las amarras que tiene esa globalización con la cultura blanca y la dominación de sectores poderosos económica y políticamente, lugares desde los que parecen las únicas lecturas posibles de la realidad, las que occidente ha construido como su verdad-poder y hoy en el saberpoder. Esa expresión de lo diferente se cruza con aquello que silencia, y es así como aparece:

- Un mundo no sólo blanco • sino también negro, mulato y multicolor (construyendo lo étnico)

- Un mundo no sólo de ricos y nobles sino también de pobres, asalariados y desempleados

- Un mundo no sólo de hombres • sino también de mujeres y homosexuales.

- Un mundo no sólo con una ciencia • sino un conocimiento en expansión con múltiples interpretaciones

- Un mundo no sólo adulto • sino también de jóvenes y niños/as con sus propios sentidos y esperanzas

- Un mundo no sólo bipolar • sino multipolar, con múltiples formas de realizar el desarrollo

- Un mundo no sólo bipartidista • sino un mundo multipartidista

- Un mundo no sólo de metrópolis sino también campesino y desplazado.

Estas múltiples manifestaciones nos muestran cómo los conflictos entre culturas en un sentido amplio (de etnia, de clase, de género, de saberes, de generaciones, de principios doctrinarios, de partidos políticos, entre otros) no pueden seguir siendo analizadas como simples relaciones de oposición, sino que se hace urgente un esfuerzo por entender cómo las 
relaciones de poder están vivas al interior de estos procesos en una lógica mucho mayor, porque han sido diferencialmente constituidas. Por ello, es necesario encontrar los mecanismos que hagan visible la manera como esas miradas unipolares, al negar y excluir lo otro han construido su poder, produciendo un discurso de la diferencia que al no tener en cuenta el poder que excluye hace que sea simplemente pluralismo, para evadir las responsabilidades en la construcción de la desigualdad.

En razón de esto, para dar un paso más allá de la mirada liberal del pluralismo, significa plantearse con urgencia un multiculturalismo crítico que, fundado en la diferencia, pueda señalar las desigualdades que se construyen allí y señalen el camino para construir posibilidades políticas que asuman como parte de su proyecto la reconstrucción de la sociedad. Es así como este multiculturalismo ${ }^{6}$ que se coloca como tarea hacer explotar el poder existente al interior del mundo unipolar para que emerjan múltiples versiones de la manera como la exclusión, la desigualdad, la segregación, son parte de un mismo continuum como proyecto occidental centrado en construir nexos de dominación. ${ }^{7}$

Por ello, el multiculturalismo crítico no acepta la diferencia como si fueran culturas que permanecen intactas, sino que reconoce en ese juego los

\footnotetext{
${ }^{6}$ Peter McLaren en su libro Multiculturalismo crítico (São Paulo. Instituto Paulo Freire-Cortez Editora. 1997) diferencia tres tipos de multiculturalismo:

a. El conservador, que plantea el mundo como una cultura común desde el grupo más fuerte, en donde no tienen cabida lenguas extranjeras, dialectos étnicos o regionales. Señala el caso de la enseñanza del castellano en California. Para ellos, la unidad nacional y la ciudadanía armoniosa son los ideales. Han construido como unidad análitica el WASP (White, Anglo Saxon Professional - persona anglosajona blanca), en quien coloca los valores afirmativos: self, creatividad, ambición, y estos niveles se elaboran desde las culturas más fuertes que eliminan otras. En el ámbito de la investigación, el rigor lo comprueban desde el carácter empírico.

b. El liberal, para el cual existe una igualdad natural, la cual debe ser realizada y garantizada por todos y en caso de que se dé la desigualdad, debe garantizarse realizar reformas para que los desiguales logren una igualdad relativa. Cuando se plantea el problema de las diferencias, éstas siempre son colocadas como relativas a raza, clase, género y sexualidad, lugares desde los cuales construyen las identidades dándole mucha fuerza al carácter personal de esas identidades.

c. El crítico, para quien las representaciones de clase, raza y género son el resultado de procesos históricos. Para comprenderlas debe hacerse un análisis de las luchas sociales más amplias en las cuales han sido constituidas. Por ello, la diversidad sólo puede ser afirmada dentro de una política de crítica y compromiso con la justicia social. Para él la diferencia siempre es un producto de la historia y los conflictos se convierten en ocasiones en la manera de contestar las manifestaciones del control de la hegemonía.

${ }^{7}$ McLaren, Peter. Multiculturalism and the Post-modern Critique. Towards a Pedagogy of Resistance and Transformation. (Fotocopia. Sin datos)
} 
riesgos de asumirse hoy en un mundo globalizado y por tanto reconoce que sus relaciones se hacen mucho más complejas, que se producen rupturas, desvíos, clausuras, encerramientos, como forma de manifestación de la diferencia. Esto significa un no al uniculturalismo, centrado en lo euroamericocéntrico, en lo androcéntrico, en lo falocéntrico, y en esa resistencia reconoce que se resiste a un universalismo que se rompe como verdad cuando se visibilizan las relaciones de poder y privilegio que constituyen. ${ }^{8}$

Una de las preguntas centrales va a ser cómo romper con la institucionalidad de la igualdad formal, que a su vez construye identidades formales y que subsumiéndonos en una unidad construida desde la forma liberal de la política apaga las diferencias. Esto va a exigir la capacidad de construir los nuevos discursos de la desigualdad para entender que la justicia no se va a dar como realidad simplemente porque una ley lo determine y ello plantea que si se quiere justicia ésta necesita ser constantemente conquistada y recreada por todos aquellos que desde una ética de la solidaridad deciden convertirla en aspecto central para la reconstrucción de la sociedad.

Resistir al universalismo que se construye a sí mismo desde la diferencia es la posibilidad de enunciar en mi acción y en mi reflexión que él no puede ser sostenido ni ética ni moralmente en la sociedad, en mi grupo social y en la experiencia personal, lo que me lanza a construir un nuevo discurso de esperanza que reconstruye las relaciones entre personas, sistema, a la vez que intenta reorganizar el tejido social. Significa en últimas que es necesario construir una nueva forma de la crítica que evite cualquier forma mediante la cual se naturalicen las relaciones de poder y privilegio. ${ }^{9}$

\footnotetext{
${ }^{8}$ Grossberg, Lawrence. We Gotta Get Out of this Place. Popular and Post-modern Culture. New York. Routledge. 1992.

${ }^{9}$ De toda esta mirada de la multiculturalidad, aparece claramente un discurso que va más allá de la desigualdad socioeconómica, que tiene como horizonte la igualdad construida sobre derechos sociales. Este discurso recoge la idea de exclusión, la cual aparece como parte de un proceso relacional, definido por normas socialmente controladas y que buscan construir un ordenamiento de relaciones sociales fundadas sobre la homogeneización. Creo que es una elaboración para estos tiempos sobre lo que significa la diferencia manejada desde procesos de poder. En ese sentido, la exclusión va a aparecer como un proceso conformado históricamente en el cual una cultura o grupo humano asume su rol de verdad, crea un abismo con la diferencia y la rechaza. Y si se cuenta con un poco de poder, la aniquila simbólica y, si puede, realmente. En los casos más leves, produce una invisibilización de ella para zafarse de la incomodidad que le produce.
} 


\section{El conflicto: punto de partida para nuestros cambios ${ }^{10}$}

Uno de los problemas centrales cuando se aborda una mirada sobre el fenómeno de lo multicultural de la sociedad globalizada, es la manera como desde el poder se intenta darle cauce a los conflictos, en la naturalización del poder es la forma sutil como se disuelve el conflicto vía pluralismo, ya que al no ver lo desigual, lo excluido, lo segregado, considera todos los conflictos expresión de sólo la diferencia.

Por ello es necesario desarrollar la capacidad de reconstruir pensamiento y acción desde una mirada que sea capaz de romper los imaginarios que han permeado una visión esencialista instalada socialmente en nuestra subjetividad, haciendo que en nuestra vida cotidiana nos comportemos ambiguamente, no siendo lo claros que decimos ser, haciendo que miremos el conflicto más bien como causante de problemas que el propiciador de transformaciones individuales y sociales.

Asumir el conflicto significa abordarlo de otra manera a como estamos acostumbrados a hacerlo, y convertirlo en generador de procesos, impugnador de verdades, reconstructor de poderes, y organizador de propuestas. Pero la dificultad mayor está en las rupturas que tenemos que realizar en nuestro accionar subjetivo y personal con seis procesos profundamente inscritos como impronta en la cultura que hemos formado en la trama histórica de nuestras sociedades y que hoy bajo el capitalismo globalizado toma el sesgo de lo universal. Estos aspectos son:

a. La verdad como esencia.

Una larga tradición que se ha desplazado desde las imágenes de lo divino al campo de la política y en los últimos tiempos impregnado el mundo de lo científico, ha ido moviéndose en un proceso de verdades absolutas donde no es posible sino establecer dos campos: el de la verdad y de la falsedad. Esta mirada, cuestionada desde diferentes concepciones de la ciencia hoy en día, con la entrada de procesos

\footnotetext{
${ }^{10}$ Retomo y amplío elementos de mi texto "La paz, una cultura que se construye", publicada en el libro Educación para la paz. Una pedagogía para consolidar la democracia social y participativa. Varios autores. Santa Fe de Bogotá. Mesa Redonda Magisterio-Red de pedagogías constructivas. 1999. Páginas 31 a 70.
} 
complejos del caos, del azar, de los construccionismos, de los sistemas abiertos, etc., nos muestra una realidad científica, social, cultural, constituida desde múltiples lugares, entregándonos una mirada más rica de verdad en construcción y en expansión. Esto no significa la negación de los elementos constituidos anteriormente, pero sí su relativización.

b. La interpretación del mundo siempre dicotómica.

Esta mirada del mundo, partiendo de la verdad (de cualquier tipo) construyó una mirada sobre lo otro diferente como el opuesto negativo de aquello que yo afirmaba. Es así como lo mío era lo bueno, lo de los otros era lo malo; yo era el científico, el otro era el ignorante; yo era el generoso, el otro era el egoísta; mi política interpretaba la sociedad global, la otra sólo al grupo de élite. Si analizamos con cuidado estas miradas dicotómicas, nos podemos dar cuenta de que ha sido el sistema fácil para descalificar.

c. La producción de cosmovisiones totalizantes.

Esa forma de la verdad y la enunciación del juicio sobre el otro va a tener una característica muy clara, en cuanto organiza miradas e interpretaciones del mundo que pretenden ser la realidad. Y confundiendo a ésta con lo real, se autocalifica como la interpretación correcta, lo que le da legitimidad para operar contra las otras interpretaciones, sin producir un diálogo que permitiera enriquecerlo, construyendo realidades más complejas y múltiples.

d. La reducción del conocimiento a procesos racionales.

El hecho de configurar lo humano desde la especificidad racional llegó a producir una reducción de otras dimensiones de la constitución de lo humano, como el deseo, el placer, lo lúdico, y éstas fueron vistas más como manifestaciones de la parte más animal de nuestro ser. Por lo tanto, durante mucho tiempo se excluyó el cuerpo y se redujeron a un segundo plano aquellos tipos de conocimiento en los cuales estuviera implicada la subjetividad de quien conocía.

Hoy se abren puertas para reconocer cómo lo conocido está implicado en el sujeto cognoscente y cómo esas otras dimensiones de lo humano también acumulan las experiencias, y desde allí desarrollan formas de 
conocer que no necesariamente se sintetizan en forma racional. Esto ha abierto una cantidad de búsquedas sobre el yo interior y las nuevas identidades del ser humano.

e. El desacuerdo como enemistad.

Hemos ido construyendo en torno a nuestras verdades, certezas a las cuales deben adherir todo el grupo humano cerca de mí, estableciendo una solidaridad de cuerpo casi feudal que me lleva, en el caso de lo personal, a que cuando alguien del grupo cercano establece diferencias con nuestros puntos de vista o avanza hacia construcciones diferentes, sentimos en el campo de la emoción una especie de ruptura mediante la cual el otro se está marchando y de que traiciona la lealtad del grupo, estableciendo en nosotros un temor a la diferencia de los próximos. El poder allí establece formas de censura para que las comunidades cercanas se construyan no haciendo explícita la diferencia.

Cada vez más la comunidad de pensamiento y acción abre caminos para comprender que el desacuerdo es un instrumento de crecimiento y que en el campo de lo humano el desacuerdo es un signo vital de la diversidad que nos enriquece y nos libera de las pretensiones de poder y dominación en la esfera social e individual sobre los otros.

f. La patriarcalidad como enunciación y acción.

El ejercicio del poder ha tomado representaciones sociales, políticas y económicas y durante mucho tiempo, de una manera invisible, una forma de explosión y segregación en el encuentro de géneros, en el cual ha construido el poder desde el predominio y control del hombre hace que su masculinidad adquiera una línea de construcción generando segregaciones que en la vida cotidiana toman formas de relación con lo femenino de inferioridad. Formas culturales que por ser hegemónicas en una larga constitución habitan en la subjetividad de hombres y mujeres de estos tiempos.

No va a ser posible instaurar procesos de cambio mientras no deconstruyamos la presencia patriarcal en nuestra subjetividad, en las prácticas sociales y en las maneras como intentamos transformar y hacer diferente esta sociedad. Este ejercicio no es fácil, porque va a requerir también un ejercicio de refundar la masculinidad y lo femenin 
g. La naturalización de la exclusión y la segregación.

En nuestra sociedad y con más fuerza en el último período neoliberal, guiado por sus dos principios fuerza: mercado e individuo, se considera al individuo perdedor en este mundo, como responsable de su destino, además produciendo un fenómeno. Explican los fenómenos de pobreza, exclusión y segregación como normales en el funcionamiento de la sociedad, generando una mirada que encuentra estos hechos como consustanciales al desarrollo de la sociedad en que vivimos, volviendo por nuevas naturalizaciones y en forma más elaborada, al viejo discurso ideológico-religioso de que pobres siempre van a existir.

h. El ascenso social y cultural como meta de vida.

Una idea del desarrollo y el sub-desarrollo fundamentado en el crecimiento como la posesión de bienes materiales nos ha colocado en la meta de tener siempre más de lo que se tiene y ansiar llegar a niveles de posesión de alguien que siento "está por encima de mí", produciendo una distorsión sobre los sentidos de la vida, a la vez que invisibiliza a quienes están "por debajo de mí", colocándome unos parámetros de ascenso social que si los logramos para todos -en ese "ideal" de vivir como los países del norte", el planeta colapsaría, como consecuencia de un modelo de desarrollo no sustentable.

Estas ocho prácticas han permeado nuestra cultura de tal manera que han construido un imaginario social del cual somos portadores y todo aquel que se ubique en una interpretación diferente a la mía queda en el terreno de las exclusiones posibles. Y si mi mirada ha sido sancionada por el poder o en estas nuevas épocas del conocimiento por el poder-saber, yo logro colocar a mi servicio toda la parafernalia de éste para producir exclusiones. Pero esto no es sólo un poder a nivel macro. Se ha convertido también en la forma de construir relaciones en el mundo inmediato o cotidiano de todas las personas. Por ello, todo lo diferente es mirado sospechosamente y rápidamente por vía del mal manejo del conflicto termina convertido en opositor o enemigo.

Este juego de imaginarios va rotulando el mundo en un juego de dos orillas, en el cual la introducción de cualquier punto de disenso que podría marcar las formas de la diferencia que enriquece como manifestación de un conflicto creativo, terminan siendo paralizantes de los procesos sociales 
en cuanto fragmenta los grupos humanos y sus comunidades en los más diversos ámbitos, llevando a construir una cultura en la cual el conflicto siempre se manifiesta no como retador y reconstructor de relaciones sino como el espacio desde el cual encasillo la mirada del otro para entrar en la lógica fácil del amigo-enemigo.

Es muy fácil de observar esto en la manera como hombres y mujeres desde nuestra infancia vamos reinsertando en nuestra vida cotidiana discursos del poder blanco, aristocrático, macho, de una verdad científica, del adulto, del mundo bipolar, del mundo bipartidista, y en últimas, teniendo prácticas y discursos de patriarcas colonizadores y racistas conquistadores, que vamos segregando y excluyendo a quienes se mueven en otro horizonte, quienes saben necesariamente nuestro mundo de representación para ser negados e invisibilizados.

Por ello, plantearnos el conflicto como central requiere una capacidad de construir diferencia, antagonismo, no certeza, que enfrentando los problemas del poder, del saber y de las formas de la exclusión y la dominación encuentra los núcleos conflictivos en el ámbito de la acción y la reflexión y los coloca en un escenario público, capaz de enfrentarlos y resolverlos. Pero construir esta cultura del conflicto significa también construir otros modelos de sociabilidad y organización social que generen la capacidad auto-reguladora de hacer emerger los conflictos en sus diferentes niveles para que las jerarquías de poder y privilegio no se reproduzcan, generando desigualdad, exclusión o segregación.

Este paso significa la capacidad de replantear la forma de la crítica que hemos hecho hasta ahora, porque ella también, hija de las formas culturales que hemos vivido e introyectado, se ha constituido como verdad excluyente y dogmática. Significa la capacidad de entrar a una crítica que es capaz de hacerse nueva cada día y, por lo tanto, provisional en la velocidad de los cambios de estos tiempos; y significa también estar crítico con uno y abierto a lo que las otras posibilidades de un mundo más amplio me entregan a mí para reconstruir.

Es importante entender que este conflicto es múltiple y no se queda sólo en el campo de lo discursivo, sino que atraviesa procesos de acción y por ello va a abrir la posibilidad en la crítica al reconocimiento de los intereses, 
y es allí donde la diferencia es politizada al ser situada en un escenario con tejido social propio y no simplemente un juego de contradicciones en la palabra, en el símbolo, en el discurso. Recuerden, no sólo en ellas, porque también son importantes todas las contradicciones.

Entrar en el conflicto significa abandonar el dualismo descalificador que hace invisible a lo diferente, a lo desigual, a lo excluido, a lo segregado, aspectos que siempre se presentan como conflictivos porque su oficio es invisibilizar al otro. Esto significa plantearnos de fondo la crisis del sujeto en el mundo globalizado. Toda la discusión sobre su autonomía, su identidad, y la entrada en juegos de permanente constitución de identidades híbridas constituidas por múltiples combinaciones culturales que producen su hibridez, replantean de fondo la manera como nos relacionamos y la manera como nuestros imaginarios han sido codificados y los principios y valores con los cuales hemos dirigido nuestras acciones.

Aprender a leer el conflicto es la capacidad de reconocer la multiculturalidad bajo sus numerosas expresiones con una profunda capacidad crítica que a la vez elabora los primeros elementos de una transformación realizada por los actores que, asumiendo el conflicto como elemento generador de mundos nuevos, es capaz de retomarlo para superar la protesta y enfrentar el dualismo como un lugar del que hay que salir para reconstruir el mundo con múltiples colores y múltiples sentidos.

Cumple un papel de reconstructor de la confianza en el otro, de la importancia del diferente, aspecto que se convertirá en eje de la reconstrucción de la solidaridad, que nos va a permitir inicialmente trabajar juntos a pesar de las muchas diferencias que tengamos, y desde allí nos unimos para enfrentar desigualdades, exclusiones.

\section{El conflicto es el duro encuentro con nuestra condición humana}

Normalmente uno de los signos de que algo anda en dificultades en nosotros, los humanos, es cuando se nos presentan algunos problemas y allí nos quejamos de que algo no anda bien en nosotros, de que normalmente en esos momentos nuestros estados de ánimo decaen, y por momentos nos resistimos a enfrentar los problemas. Pero cuando estas situaciones se nos presentan, no son más que las manifestaciones de que 
la vida nuestra crece mediante la lucha, el desafío, ya que cuando solucionamos estos problemas normalmente emergen otros y un poco a lo largo de la vida nos vamos especializando en resolver problemas, en enfrentarlos y cada cual va encontrando la manera de encararlos.

Por eso, pudiéramos decir que el conflicto nos recuerda que somos seres llenos de luchas contra adversarios internos, externos, y en ocasiones contra adversarios virtuales que hemos constituido para enfrentar la dureza de nuestra construcción. Es decir, vamos teniendo la certeza de que ser humano es fundamentalmente conocer el conflicto.

\section{Nos pregunta por ¿quién soy?}

Cuando reconocemos la experiencia del problema y del conflicto siempre nos queda la certeza de que ese encuentro es siempre una experiencia personal. Parece que hubiéramos nacido para él y es allí donde reconocemos la raíz del conflicto, que surge del crecimiento al que me veo abocado cada día de acuerdo con las formas sociales de organización que me plantean:

- Ser más, que es la pregunta por ¿quién soy? Y la manera como me planteo mis sentidos en mi cultura y en el mundo que me rodea;

- Ser más con otros, que se refiere a los procesos de convivencia en los cuales estoy inscrito y debo participar junto a grupos o comunidades para que la obra se desarrolle;

- saber más, es la relación a la esfera del conocimiento, en donde me pregunto por los saberes de uso social y personal que tengo y debo tener para vivir en este mundo de hoy;

- tener más, es la presencia en la esfera de los bienes y el lugar de ellos en mi vida, alertándome sobre la necesidad específica de su posesión para conseguir los intereses que me plantea el ¿quién soy?

- querer más, es la manifestación en el campo de los afectos y que hace visible no sólo lo que siento, sino la manera como materializo esos quereres bajo la forma de deseo; y

- hacer más, se refiere a las exigencias cotidianas de mis prácticas de vida y en últimas, a las exigencias profesionales y productivas que van en una secuencia de hacer, hacer más y hacer distinto. 
Estos seis aspectos presentes en toda acción humana y en toda subjetividad surgen de la construcción día a día de lo humano, en donde la tensión entre necesidades sociales y necesidades individuales construye un camino intermedio de acción y de sentido. Esas formas sociales construyen una tensión que termina siendo una confrontación con la fidelidad a lo que nosotros queremos ser y a la manera como queremos enrutar nuestra vida desde las exigencias de la sociedad.

Por eso, cuando el conflicto aparece, nos está señalando que en la aparente autosuficiencia no tenemos un control total sobre nuestras vidas y los procesos que agenciamos en ellas y es el momento cuando aparece la paradoja más fuerte: quedarnos en donde estamos o saber que si lo enfrentamos emprenderemos un camino más allá de nuestros límites.

Esto significa una opción anterior y es reconocernos a nosotros mismos como seres incompletos en permanente crecimiento, y el conflicto lo que me avizora es la necesidad de trabajar mi horizonte de sentido, reconocer hacia dónde voy desde lo que soy, a la luz de las preguntas y los interrogantes que a la fidelidad con mi vida hacen aspectos, personas, elementos, experiencias, en donde lo otro diferente a mí emerge enriqueciendo mi ser.

\section{No siempre somos tan claros}

Por eso, siempre el conflicto nos hace referencia a que algo importante está pasando en nuestras vidas y que prestarle atención es tener la capacidad de revisar la esfera de mi yo, que ha decidido entrar en el terreno de la duda. Por eso, siempre nos va a estar hablando de los claroscuros que hay en nuestra existencia y para nosotros, hechos en una cultura de la verdad, de la claridad, de las ideas y los seres claros y distintos.

Es difícil reconocer que tenemos una zona oscura y para nosotros, educados en estas maneras de las certezas, reconocer que el conflicto introduce una forma ambigua que me saca de mis certezas significa de alguna manera abrirme a la dualidad y aceptar la incertidumbre como condición del crecimiento. Pero lo más difícil, nosotros que siempre hemos aprendido a ganar o a perder, es la capacidad de aprender que la respuesta nueva no está en una de las dos cosas, sino en la disputa y en la manera como ha 
construido la duda sobre lugares aparentemente claros, donde no se gana o se pierde, sino que se aprende y se construye.

Por eso, el conflicto va a aparecer como un entramado a través del cual emerge el yo real. Ese no siempre compuesto de las luces y claridades, sino también de las sombras que yo a veces oculto y que no aparecen porque no ha encontrado el choque con lo diferente que lo haga emerger. En ese sentido, el conflicto no es la transformación misma que se opera en mí, pero va a ser la plataforma que constituya la base de las transformaciones que yo debo emprender.

En razón de ello, el conflicto no es bueno o malo, es moralmente neutro. Va a hacer que sea bueno o malo la manera como lo asumimos y lo colocamos en el entramado social y usándolo en circunstancias de poder nos sirve para oprimir, segregar, dominar, censurar, excluir, invisibilizar a los otros o encubrir mi zona oscura o mis maneras de relacionarme ejerciendo poder.

\section{También dolor y sufrimiento}

El conflicto nos está hablando de que, ser humano, no es un camino de rosas; que asumir el conflicto significa asumir niveles diferenciados de sufrimiento, con sus consabidas manifestaciones del miedo, el dolor, la pasión, la ira. Esto va a exigir de nosotros una lucha permanente por encontrar quiénes somos nosotros mismos y cómo construimos nuestras fidelidades, así como el lugar del otro y los otros en nuestra vida, y reconocer que estando el conflicto permanentemente en nuestra vida, aprender a manejarlo es un acto de aprendizaje que requiere ir al encuentro de nosotros mismos desde las más variadas posibilidades.

Por eso, cuando pasa el conflicto podemos, mirando hacia atrás, reconocer el costo del dolor como parte de nuestra construcción y de nuestra cimentación, pero cuando se avizora el nuevo conflicto este nos está avisando que somos complejidad no controlada totalmente y que esta nos avisa que será posible ser de otra manera, es decir, inaugura la utopía individual. El conflicto, al fortalecer el aprender a saber que seremos de otra manera, se convierte en el instrumento principal de crecimiento y de la marcha como humanos por ser cada vez más fieles a nosotros mismos. Por ello no queda sino reconocer que es una permanente en nuestras vidas. 


\section{El problema no es el conflicto, sólo su manifestación}

Normalmente reaccionamos cuando el conflicto adquiere manifestaciones en nuestra condición humana a través de la rabia, el dolor, el sufrimiento, y corremos a solucionar la situación que lo ha creado. Por ello pasamos la vida solucionando problemas, sin ir a las razones de fondo que están precisamente en la acumulación de los elementos constitutivos del conflicto, que son el verdadero epicentro de aquello que se manifiesta en nuestra vida cotidiana. Podemos hacer el símil del terremoto, en donde vemos sus desastres, pero sus verdaderas causas hay que buscarlas muchos kilómetros bajo tierra.

Por ello no se puede confundir el problema con el conflicto. En este último, la condición humana va poco a poco tejiendo la urdimbre de nuestra condición y crecimiento. Es desde él como lo nuevo hace su aparición, mostrándonos que podemos ser diferentes sin miedo a ese cambio. Es la emergencia de la utopía en la esfera de la individuación, hay otro lugar hacia el cual ir.

En ese sentido, podemos afirmar que el conflicto es un sistema complejo que debe aprender a descubrirse. No es el suceso que emerge en nuestra vida como problema, no es el simple suceso a través de lo cual se manifesta: miedo, desconfianza, enemistad, odio. Éstos son elementos que lo alimentan y son parte de su dinámica, pero no es el conflicto mismo, ya que esa manifestación es la muestra de que él está escapando por nuestras grietas: miedo, cólera, arrogancia, aburrimiento.

Buscamos evadir el problema, queremos que desaparezca, siempre. Cuando él viene desde el conflicto, lo evadimos, lo desaparecemos, hasta que el problema, por ser manifestación del conflicto, toma caminos de empeoramiento y nos desborda, hace crisis y en ello lo que se hace visible es que tenemos una confrontación con nuestra interioridad, con aquello que decimos ser.

En esta perspectiva es que afirmamos que se produce un enlace entre la manera como resolvemos los conflictos en lo individual y la manera como se produce esto en lo social, generando una incapacidad para enfrentar el conflicto. Por motivo de lo que se solicita para este seminario y de espacio, 
no desarrollo esos otros aspectos que permiten construir ese asumir educativamente el conflicto en detalle y que he denominado del diálogo a la negociación cultural o un tratamiento integral del conflicto.

Para asumirlo integralmente, es necesario no resolverlo como una simple situación personal. Es necesario un proceso que una lo micro, lo meso y lo macro, y ello significa deconstruir los imaginarios culturales de poder existentes en nuestras prácticas cotidianas, como esas primeras formas que generan socialmente control y prolongación de las formas sociales de poder, atizador de la resolución violenta de los conflictos. Por ello, para cambiar en estos tiempos es necesario abrirnos a desaprender muchos de esos procesos que culturalmente no permiten abrirnos al conflicto como generador de nuevas formas de vida social.

\section{Agenda para la escuela como constructora permanente de paz y reguladora del conflicto}

a. Rescatar la escuela como un lugar de socialización cultural y política, no solo de instrucción y de estándares y competencias. Ello requiere un ejercicio de pertinencia y de territorialización a los contextos mediante un ejercicio de pedagogías críticas y situadas.

b. Una escuela que trabaja la vulnerabilidad humana y social y la convierte en un espacio de solidaridad y de aprendizaje colaborativo en el cual la ética del cuidado toma forma desde la acogida hasta la vinculación con el contexto.

c. Una escuela que reconstruye el arraigo para enfrentar el desarraigo que homogeniza, permitiendo la construcción de subjetividades e identidades que en medio de la fragmentación de este tiempo hacen visible en el ejercicio pedagógico la capacidad de trascendencia y el enfrentar el ejercicio descolonizador presente en el currículo.

d. Una escuela que tramita los conflictos como fundamento de construir consciencia crítica y aprender a tener mejores conflictos basados en una pedagogía de la diferencia que construye la complementariedad como fundamento de un tejido social que nunca será más para la guerra.

e. Una escuela que valora múltiples mundos y construye el nexo entre lo universal y lo pluriverso haciendo a sus participantes ciudadanos del mundo e hijos de la aldea en donde tienen lugar los saberes propios fundados en una pedagogía del diálogo de saberes y la negociación cultural, en el cual el buen vivir nos permite salir del antropocentrismo. 
f. Una escuela que se convierte en co-constructora de comunidad y generadora del sentido de la vida que hace real la acogida del otro y diferente pero también establece una relación con la naturaleza dando lugar a las formas del biocentrismo.

g. Una escuela que se hace sanadora de los dolores que la violencia ha dejado en los cuerpos, en las mentes y en los deseos, estableciendo pedagogías que trabajan el cuerpo y hacen realidad de que es el primer territorio de paz.

h. Una escuela que construye unas nuevas maneras de lo ético y ella misma, saliendo de la homogenización, construye los nuevos sentidos desde el rostro del diferente y el diverso y hace real que somos humanamente diferentes, culturalmente diversos y que debemos luchar para no ser socialmente excluidos.

i. Una escuela que renuncia a la instrucción y formas limitadas de entender lo humano y para ello constituye sistemas de mediación desde una comprensión integral de lo humano, y para ello da forma a una comprensión de las capacidades que reordena derechos, teorías, metodologías, para hacer real esa escuela hecha por sus actores.

j. Una escuela que construye pedagogías en las diferentes áreas del conocimiento que atraviesan transversalmente sus prácticas para construir educativamente el conflicto y ello significa darle forma a las geopedagogías, que les va a permitir ir más allá de los modelos o reiteraciones didácticas para convertir al actor y actora de ella en productores de saber y conocimiento. En ese sentido, es una escuela empoderante de comunidades.

Si asumimos la tarea con el rigor suficiente y en el reconocimiento de la tradición en la que hemos abrevado de las pedagogías críticas y de la educación popular, las tareas educativas de este tiempo se convierten en una condición privilegiada para dar forma desde este aquí y ahora a un pensamiento propio que desde hace un tiempo con más fuerza gime por dar forma a eso que somos y nos hace tan particularmente específicos para relacionarnos con la universalidad desde nuestras particularidades. Porque como bien ya nos lo decía nuestro maestro peruano:

"Vivimos la emergencia de un momento histórico sin precedentes, en el que tal vez por primera vez en más de quinientos años de subordinación, silencio y colonialismo emerge la posibilidad de otro horizonte de sentido histórico." Aníbal Quijano ${ }^{10}$

\footnotetext{
${ }^{10}$ Quijano, A. América Latina. Hacia un nuevo sentido histórico. En: León, I. (Coord.) Sumak Kawsay. Buen vivir y cambios civilizatorios. Quito. FEDAEPS. 2010. Pp. 55-71.
} 